\title{
Dual Port Disc Monopole Antenna for Wide-Band MIMO Based Wireless Applications
}

\begin{tabular}{|r|l|}
\hline Journal: & Microwave and Optical Technology Letters \\
\hline Manuscript ID & MOP-17-0550 \\
\hline Wiley - Manuscript type: & Research Article \\
\hline Date Submitted by the Author: & $23-$ Apr-2017 \\
\hline Keywords: & Dual port antenna, Wide bandwidth, Orthogonal polarization, RF isolation \\
\hline & \\
\hline
\end{tabular}

SCHOLARONE ${ }^{\text {M }}$

Manuscripts 


\title{
Dual Port Disc Monopole Antenna for Wide-Band MIMO Based Wireless Applications
}

\author{
Haq Nawaz and Ibrahim Tekin \\ Electronics Engineering, Sabanci University \\ 34956, Istanbul, Turkey \\ e-mail: hnawaz@sabanciuniv.edu, tekin@,sabanciuniv.edu \\ Phone: +90 216 4839534, Fax: +90 2164839550
}

\begin{abstract}
In this paper, design and implementation of a wide-band dual port monopole antenna based on single circular disc radiating element has been presented for Multi Input Multi Output (MIMO) configured 4G mobile and wireless communication systems. The proposed antenna uses a partial ground plane with two rectangular grooves which lie exactly below the respective $50 \Omega$ microstrip feeding lines in order to obtain enhanced antenna's impedance bandwidth of $2-6 \mathrm{GHz}$. A circular cut with $14 \mathrm{~mm}$ radius and centred at intersection of two partial rectangular ground planes is etched to reduce port to port RF coupling. The implemented dual port monopole antenna on $1.575 \mathrm{~mm}$ thick RT/Duroid ${ }^{\circledR} 5880$ substrate (with $\varepsilon=2.2$, tangent loss $=.001$ ) provides more than $15 \mathrm{~dB}$ RF interport isolation for antenna's $10 \mathrm{~dB}$ impedance bandwidth of $2-6 \mathrm{GHz}$ with measured gain variations of $2-6 \mathrm{dBi}$ for each port excitation. In addition to interport isolation measurement for dual port antenna, the envelope correlation coefficient over the required frequency range has been calculated and plotted using $S_{11}, S_{22}$ and $S_{21}$ measurement results to endorse the performance of dual port implemented antenna for diversity applications.
\end{abstract}

Key words: Dual port antenna, Wide bandwidth, Orthogonal polarization, RF isolation 


\section{Introduction}

Wideband mobile and wireless communication systems with high data rate capacity along with reliable communication link performance are in great demand for current fast growing wireless applications [1]. Multiple Input Multiple Output (MIMO) technology improves the data throughput of wireless and mobile communication systems by deploying radio transceivers with multiple antennas to transmit and receive RF signals in rich scattered wireless environments [2-3]. MIMO techniques accomplish the task of improvement in data throughput and system capacity through spatially separated multiple wireless channels working at same carrier frequency (uncorrelated signals) and without additional transmit power requirements in Non Line of Sight (NLOS) communications [1],[4]. MIMO techniques are also very useful to improve the performance of wireless and mobile communication systems by minimizing the multi path propagation effect [5-6].

The MIMO antenna plays an important role to improve the overall performance of MIMO systems. Although, MIMO technology improves the capacity and reliability of wireless systems but the mutual coupling between multiple antennas degrades the obtainable MIMO performances due to increased signal correlation between multiple radio signals [7]. The coupling can be reduced by placing multiple antennas with large spatial displacements but it prevents the realization of compact transceiver [8]. The effect of mutual coupling can not be ignored in order to realize a compact MIMO transceiver where multiple antennas with minimum inter spacing are required to be fabricated on same substrate [1]. Realization of a compact MIMO antenna with required interport isolation is a challenging task [1].

The printed antennas are preferred for MIMO transceivers due to their ease of integration and low cast. For conventional compact MIMO transceivers, sufficiently separated multiple planar radiating elements are deployed and either isolation improvement techniques [9-19] or decoupling networks [20-21] are used to achieve required amount of interport 
isolation for MIMO applications. For example, the antenna using two folded monopoles presented in [9] operates in 2.30-2.39 GHz frequency range and uses additional ground wall with connecting line to decrease the mutual coupling between antennas. A printed diversity monopole antenna for $2.4 \mathrm{GHz}$ WLAN operation band is presented in [10]. It deploys Tshaped ground plane between two orthogonal linear monopoles for ports decoupling. A negative group delay based correlation reduction technique for closely spaced antennas technique has been proposed in [11] which reduces mutual coupling between antennas and also un-correlates the radiation characteristic of antennas. A compact MIMO antenna using two planar-monopole antenna elements has been presented in [12] for portable UWB applications. In this design, microstrip feed lines have been used to excite the two orthogonally placed antenna elements. Two long protruding ground stubs etched in ground plane improve antenna's impedance bandwidth and reduce the mutual coupling. A $2.4 \mathrm{GHz}$ compact MIMO structure has been presented in [13], which uses two different types of radiating elements. It uses one proximity coupled square ring patch antenna co-located with probe fed PIFA. Both radiators are designed to work at $2.4 \mathrm{GHz}$ WLAN frequency and high inter-port isolation (below $25 \mathrm{~dB}$ ) is obtained through orthogonal polarization. In [14], a dual port planar canonical antenna is presented which uses folded slots as radiating elements.Coupling parasitic elemenets between canonical antennas have been used for field cancellation to improve the isolation. MIMO antennas with even number of ports can be designed by replicating this proposed dual port planar canonical antenna. A compact multipleinput multiple-output (MIMO) antenna with low correlation for UWB applications has been presented in [15]. The proposed structure is comprised of two identical radiating elements fed through 50 ohms microstrip lines and placed over half sized ground plane which is triangularly trimmed on two edges adjacent to radiating element to achieve better input impedance. The orthogonal placement of two antenna elements provides good interport 
isolation. The work in [16] presents a wideband isolation technique with neutralization lines for two crescent shaped printed monopole antennas placed very close to each other. The proposed antenna provides high isolation over $2.4-4.2 \mathrm{GHz}$ frequency band. Two antennas configuration, each comprised of two radiating elements has been presented in [17]. One configuration uses two parallel placed radiating element while the other one utilizes reverse parallel placement of antenna elements. Inverted T-shaped stubs have been used to obtain low port to port coupling over UWB frequency range. A novel neutralization technique based on two defected ground structures (a line slot and T-shaped slot etched on the ground plane) has been used in [18] to reduce the coupling between two UWB slot antennas. An ultra wideband MIMO antenna array has been presented in [19] to achieve $21 \mathrm{~dB}$ isolation over $2.5-12 \mathrm{GHz}$ frequency range by exploiting polarization diversity of two straight edged monopole radiator fed with arced feeding mechanism and placed over partial ground planes. Some antennas deploy external decoupling networks to suppress mutual coupling between elements and such decoupling networks are either based on circuit approach [20] or use lumped elements [21] to obtain improved interport isolation. For example, a circuit based technique has been used in [20] to increase the isolation between two strongly coupled antennas while a lumped elements technique has been presented in [21] to reduce the coupling between two closely packed antennas. These techniques may also be deployed for MIMO antennas.

In contrast to above reviewed research works [9-21] where multiple antenna elements are incorporated in to one antenna design or etched on same substrate to realize a compact MIMO antenna, single antenna element with multiple RF isolated feeding ports can be used in more compact form for MIMO applications. Such configuration is termed as isolated mode antenna (iMAT) [22]. Such structures excite different propagating modes in antenna for feeding from each port to reduce mutual coupling between ports [23-27]. For example, a novel dual port, single element antenna for 4G MIMO terminals based on iMAT idea has 
been proposed and analysed in [23]. The concept of iMAT antenna has also been used in [24] for U-shaped single element antenna to obtain improved port to port isolation performance as compared to compact two elements monopole antenna. A dual fed compact ultra-wideband microstrip monopole antenna with reconfigurable polarisation capability has been presented in [25] for cognitive radio systems where two orthogonal feeds using different transmission line technology have been used to improve RF isolation between two ports. One port uses $50 \Omega$ feed line using coplanar waveguide (CPW) structure while the other port excites the radiating patch using $50 \Omega$ Microstrip (MS) feed line. The proposed antenna provides more than $25 \mathrm{~dB}$ port to port isolation for $3.1 \mathrm{GHz}$ to $10.6 \mathrm{GHz}$ bandwidth based on a reflection coefficient of less than $-10 \mathrm{~dB}$. A dual-polarized MIMO antenna proposed in [26] for indoor wireless access point applications uses two perpendicular coplanar waveguide fed ports in order to excite two orthogonally polarized modes. Implemented antenna structure utilizes stepped cut at four corners (SCFC) technique which obtains required bandwidth by modifying the shape of radiating patch. Implemented antenna on FR-4 substrate achieves around $15 \mathrm{~dB}$ interport isolation for $10 \mathrm{~dB}$ impedance bandwidth of $900 \mathrm{MHz}$ to $2.7 \mathrm{GHz}$. A $2.4 \mathrm{GHz}$ dual port microstrip antenna which uses external loop in order to achieve around $75 \mathrm{~dB}$ port to port peak isolation has been presented in [27] for in band full duplex applications. Implemented antenna achieves more than $40 \mathrm{~dB}$ interport isolation in $50 \mathrm{MHz}$ bandwidth.

Most of reported antenna works in literature as reviewed above are either narrow band structures or focus on MIMO antennas for UWB applications with lower cut-off frequency of 3.1GHz. Such antenna structures are unable to support MIMO applications with operating frequencies around $2.4 \mathrm{GHz}$ including $802.11 \mathrm{~b}, 802.11 \mathrm{~g}, 2.4 \mathrm{GHz} 802.11 \mathrm{n}, 2.5 \mathrm{GHz}$ WiMax and LTE technology). In this work, dual port monopole antenna based on single circular disc radiator has been designed and its parametric study has been carried out to obtain required impedance bandwidth of $2-6 \mathrm{GHz}$ and more than $15 \mathrm{~dB}$ interport $\mathrm{RF}$ isolation. The 
implemented antenna supports $2-6 \mathrm{GHz}$ MIMO applications including $2.4 \mathrm{GHz}$ operating frequency. As the obtainable bandwidth for single element based MIMO antennas depends upon many factors including feeding techniques and size of partial ground plane but the shape and size of single radiating element plays a critical role in this regard [28]. Thus, wideband planar single element should be selected as it could be potential wideband MIMO antenna when fed through multiple ports. In this work, we have selected circular planar radiating element as it provides better impedance bandwidth [29]. The optimized dual port antenna has been implemented on $1.575 \mathrm{~mm}$ thick RT/Duroid $\AA 5880$ substrate to validate the simulation results. Measured transmission coefficient $\left(\mathrm{S}_{12}\right.$ or $\left.\mathrm{S}_{21}\right)$ and calculated correlation coefficient have been used as two metrics to evaluate the interport RF isolation performance for intended impedance bandwidth of 2-6GHz for implemented dual port single element circular disc monopole antenna.

The rest of this paper has been organised as follows: Section 2 provides the design, simulation, parametric optimization study and measured $10 \mathrm{~dB}$ impedance bandwidth results for single port circular monopole antenna on which our proposed and implemented dual port monopole antenna is based on. Design and HFSS simulation for optimized matching and interport RF isolation along with implementation details of dual port monopole antenna based on single circular element are presented in section 3. Measured input impedance bandwidth for each port, port to port RF isolation and gain measurement results are discussed in section 4. Calculated envelope correlation coefficient results using simulated and measured Sparameters for dual port antenna are discussed in same section. Finally, the paper is concluded in section 5 .

\section{Single port circular disc monopole antenna}

As our dual port monopole antenna is based on single radiating element so first of all a single port circular disc monopole antenna has been designed and its performance is evaluated 
in order to implement dual port antenna by adding second port to single port antenna and interport coupling has bee suppressed by modifying the partial ground plane. The structure of single port circular disc monopole antenna is shown in Fig.1 where $r$ and $\mathrm{Lg}$ represent the radius of circular disc and width of ground plane respectively. The optimized values of these two parameters are obtained through HFSS simulations in order to obtain required input impedance performance of antenna.
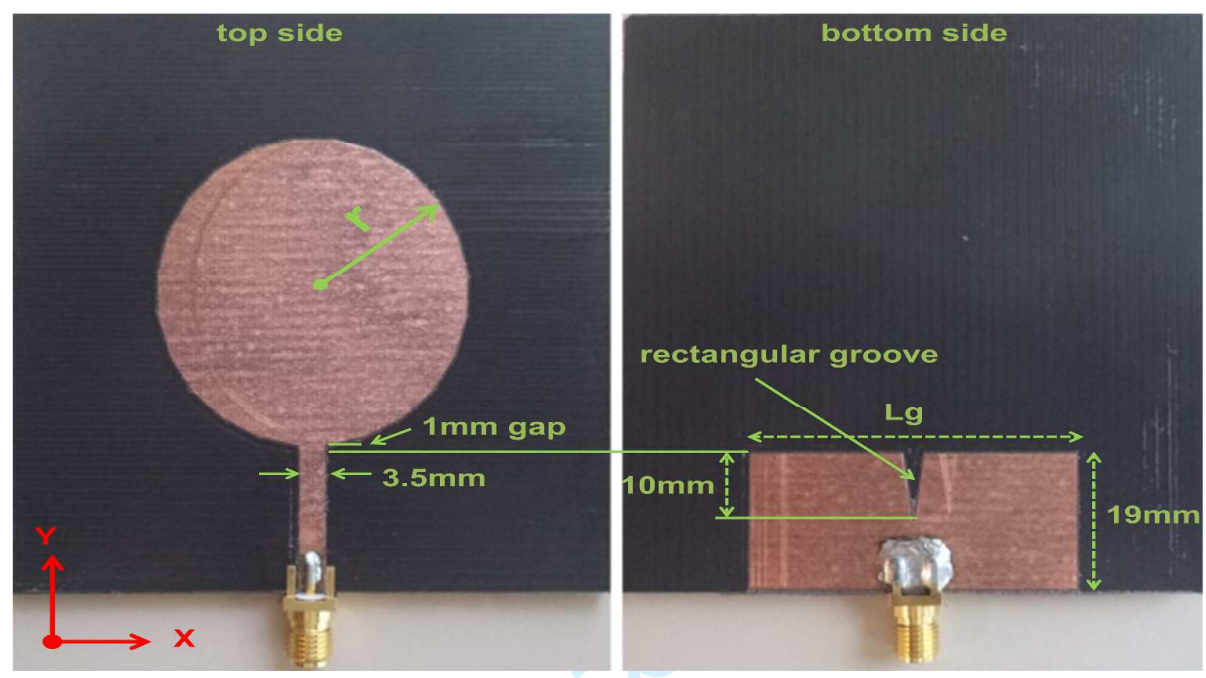

Fig. 1. Single port circular disc monopole antenna with rectangular groove in partial ground plane

Circular disc is excited through $3.5 \mathrm{~mm}$ wide and $20 \mathrm{~mm}(50 \Omega)$ long microstrip line. The radius (r) of circular radiating element defines the lower cut-off frequency for antenna's $10 \mathrm{~dB}$ impedance bandwidth [30] as endorsed by HFSS simulation results shown in Fig.2 for different value of radius (r) of circular disc radiating element. The lower cut-off frequency of antenna's $10 \mathrm{~dB}$ bandwidth shifts from $1.766 \mathrm{GHz}$ to $2.258 \mathrm{GHz}$ when radius of circular disc is varied from $20 \mathrm{~mm}$ to $14 \mathrm{~mm}$. The radius of circular radiating element is fixed to $20 \mathrm{~mm}$ for our design in order to get lower frequency below $2 \mathrm{GHz}$. A $3.5 \mathrm{~mm}$ wide and $10 \mathrm{~mm}$ deep rectangular groove has been placed exactly below the antenna feeding line to get extended 10dB input impedance bandwidth [31]. 


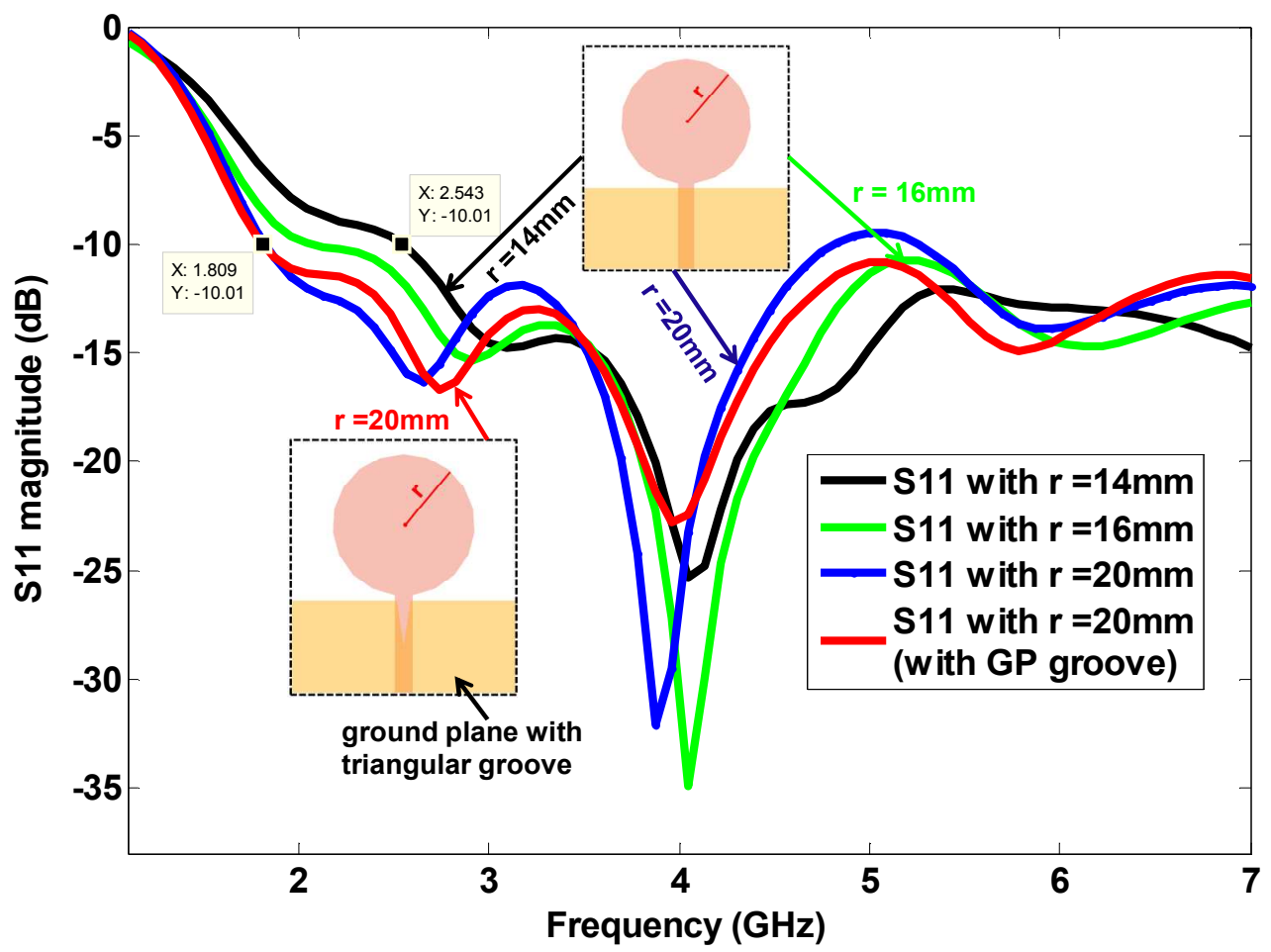

Fig. 2. Simulated S11 variations with different values of circular disc radius (r)

The size of partial ground plane $(\mathrm{Lg})$ also affects the impedance bandwidth of antenna in addition to spacing/gap between radiating element and ground plane. For our antenna, there is $1 \mathrm{~mm}$ gap between ground plane and circular disc. Optimized ground plane dimensions are obtained by HFSS simulations for different values of ground plane's width (Lg) as shown in Fig.3. For smaller values of $\mathrm{L}_{\mathrm{g}}$, input matching of antenna deteriorates around $3 \mathrm{GHz}$ but it improves at higher frequencies starting from $4 \mathrm{GHz}$ as clearly visible from Fig. 3 for $\mathrm{L}_{\mathrm{g}}=44 \mathrm{~mm}$. On the other hand, for larger values of $\mathrm{L}_{\mathrm{g}}$, antenna's matching degrades significantly in frequency range of $4-5 \mathrm{GHz}$ as clearly depicted for $\mathrm{L}_{\mathrm{g}}=48 \mathrm{~mm}$. Thus, the optimized dimensions of partial ground plane are obtained as $19 \mathrm{mmx} 44 \mathrm{~mm}$. The optimized antenna design has been implemented using $1.575 \mathrm{~mm}$ thick RT/Duroid ${ }^{\circledR} 5880$ substrate (with $\varepsilon=2.2$, tangent loss $=.001$ ) as shown in Fig. 1 with $\mathrm{r}=20 \mathrm{~mm}$ and $\mathrm{Lg}=44$. 


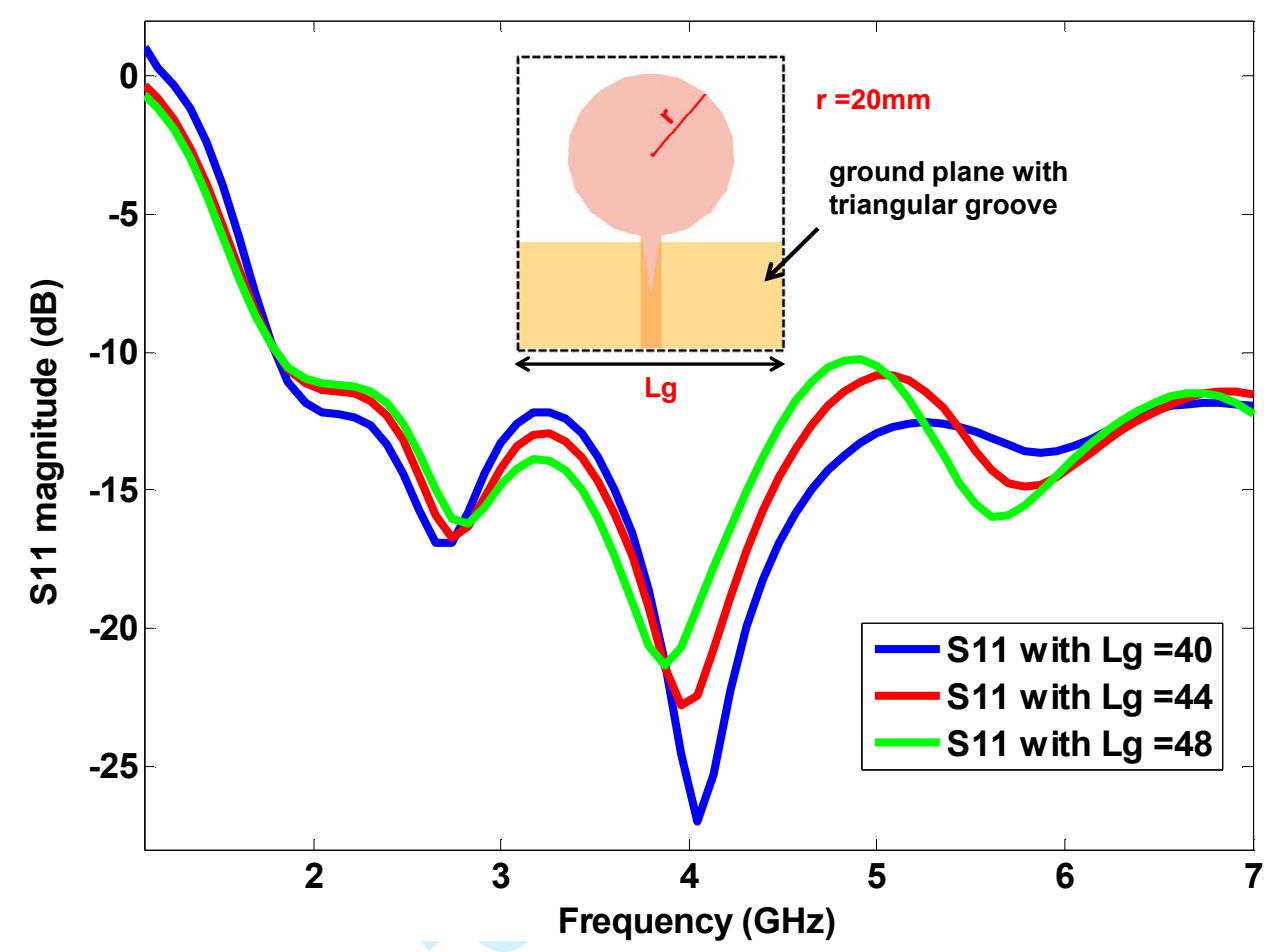

Fig. 3. Simulated $S_{11}$ for different values of ground plane width (Lg)

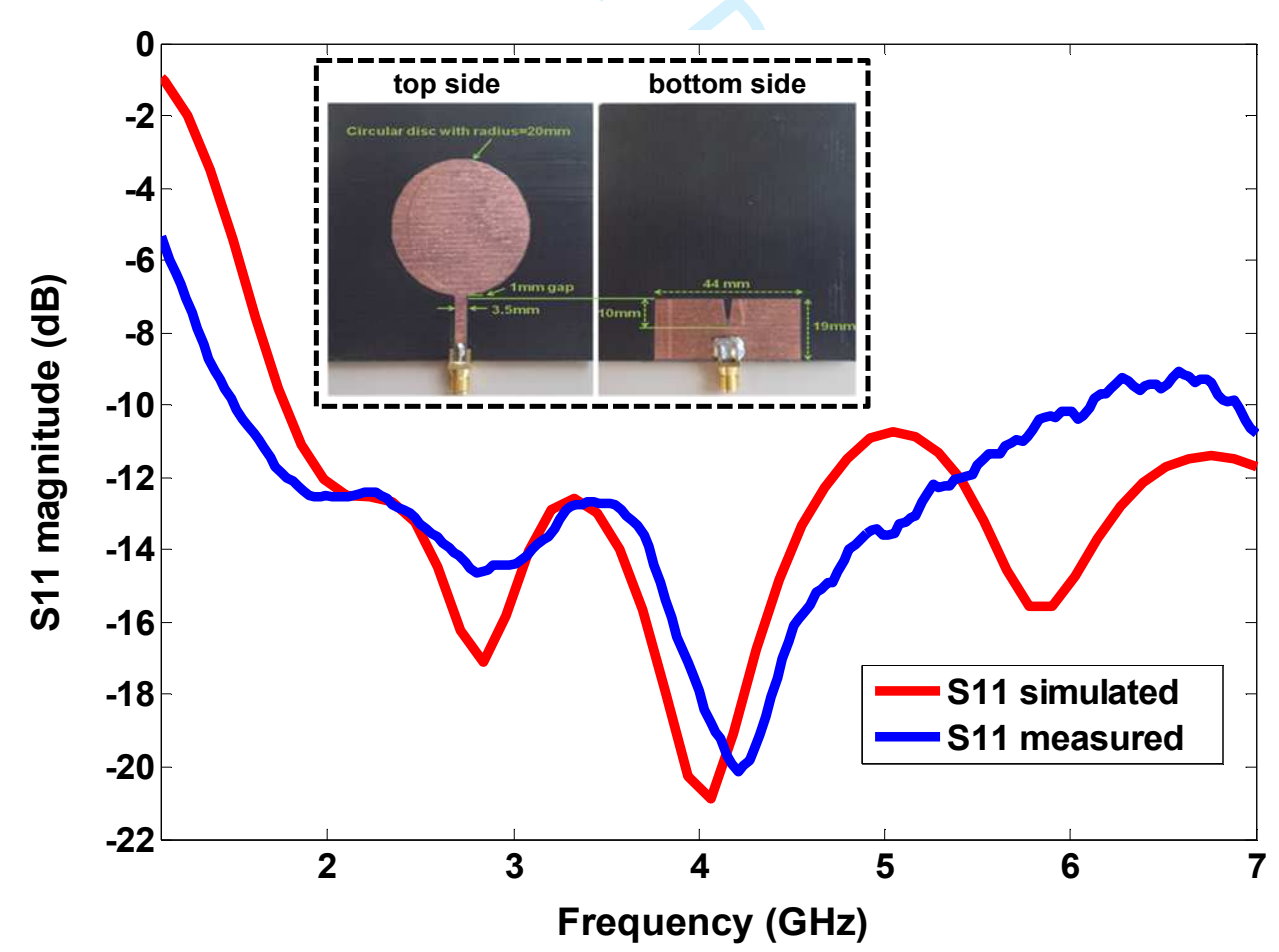

Fig. 4. Simulated vs. measured S11 for implemented single port circular monopole antenna 
HFSS simulation and measured input matching (S11) results for antenna implemented with optimized dimensions are shown in Fig.4. Measured 10dB impedance bandwidth for implemented single port circular disc antenna is $1.5 \mathrm{GHz}$ to $6 \mathrm{GHz}$. HFSS simulated Peak Realized gain for Single port circular monopole antenna is also shown in Fig.5. The simulated gain varies between $3.5-6.6 \mathrm{dBi}$ in $2-6 \mathrm{GHz}$ frequency range.

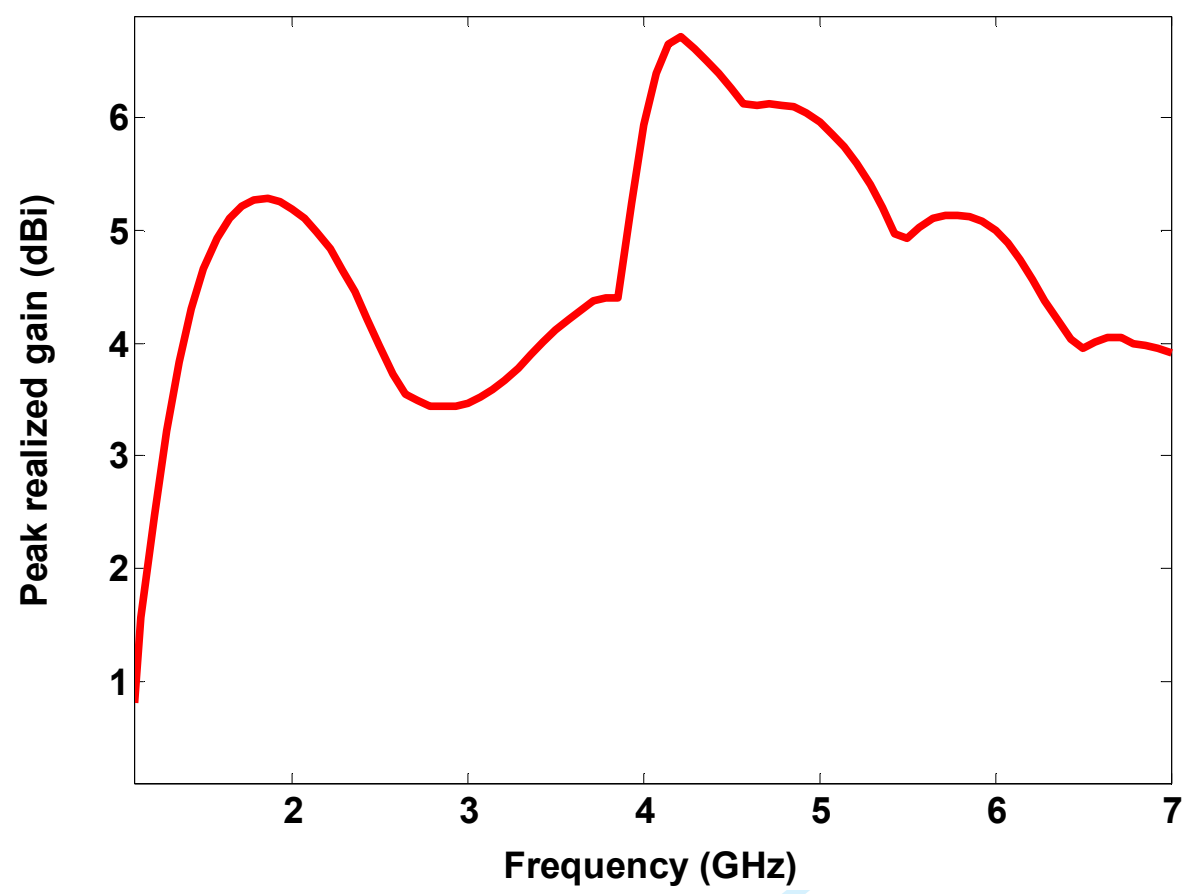

Fig. 5. HFSS simulated peak realized gain for single port circular monopole antenna

\section{Dual port single element based circular disc monopole antenna}

The dual port circular monopole antenna design is based on single port circular monopole antenna prototype as stated earlier. As shown in Fig.6, the radius of circular radiating element is $20 \mathrm{~mm}$ with $3.5 \mathrm{~mm}$ wide and $20 \mathrm{~mm}$ long feed line to excite the radiating element from each port. There is $1 \mathrm{~mm}$ gap between ground plane and radiating element. A $3.5 \mathrm{~mm}$ wide and $10 \mathrm{~mm}$ deep rectangular groove is again placed exactly below the each feeding line of antenna to get extended $10 \mathrm{~dB}$ input impedance bandwidth as is the case with single port monopole antenna prototype. 

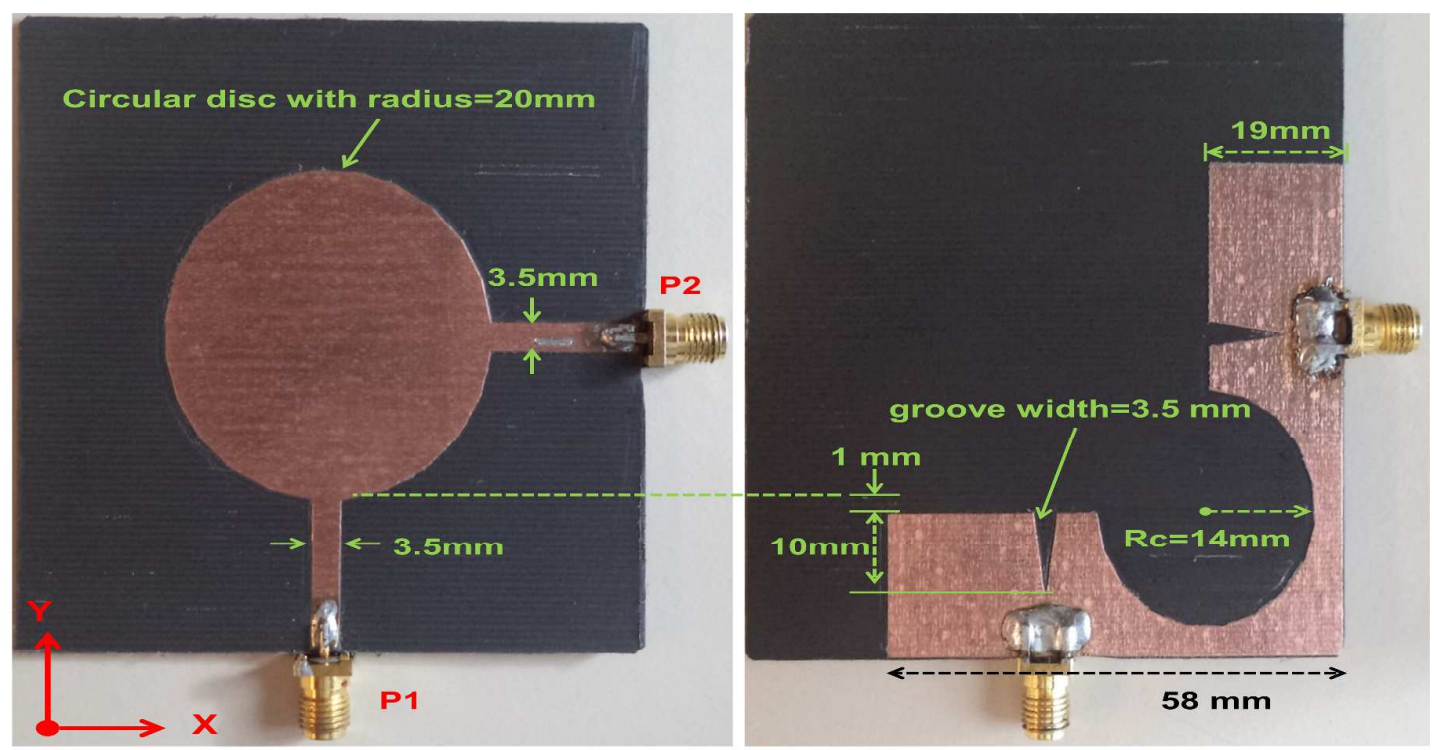

Fig. 6. Dual port monopole antenna based on single circular disc element with circular cut of radius $\mathrm{Rc}$ in ground plane

Additionally, a circular cut of radius Rc in ground plane has been etched to obstruct the currents path between the two ports to enhance the interport isolation. As shown in Fig.7(b) by surface currents distributions, the mutual coupling is significantly reduced by circular cut etched in ground plane as compared to antenna structure without circular cut in ground plane shown in Fig.7 (a).

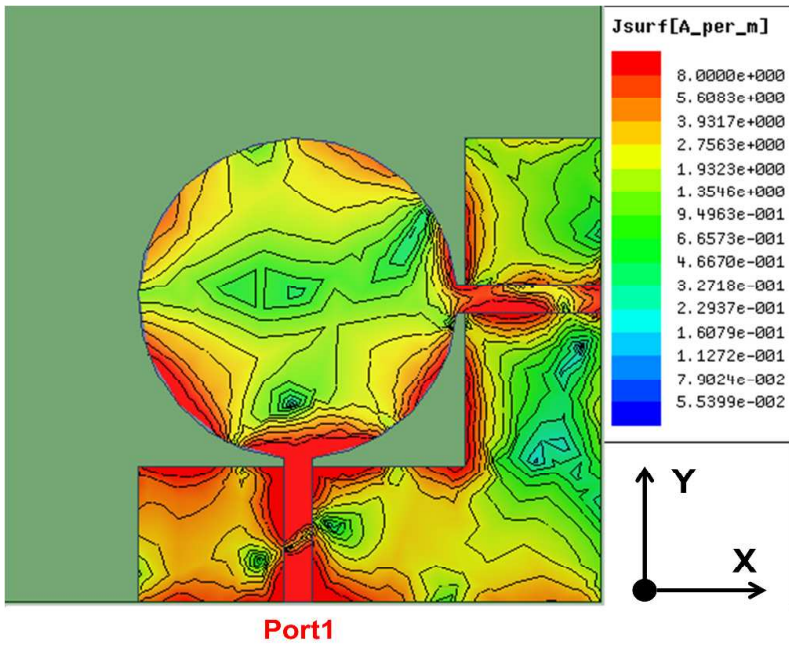

(a)

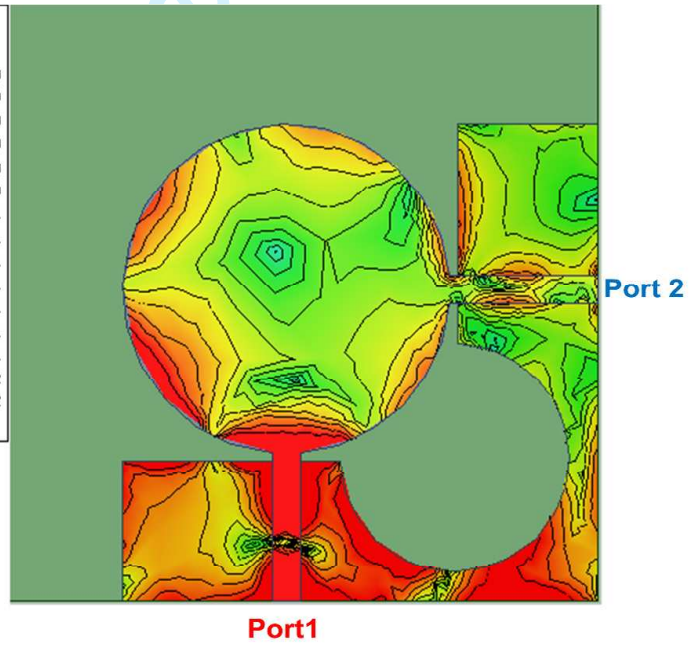

(b)

Fig. 7. Current distributions for proposed dual port circular disc antenna at $6 \mathrm{GHz}$ with port 1 excitation (a) without circular cut (b)with $\mathrm{Rc}=14 \mathrm{~mm}$ circular cut in ground plane 
The dimensions of ground plan slot $\left(\mathrm{R}_{\mathrm{c}}\right)$ have been optimized by HFSS simulations to achieve improved port to port isolation $\left(\mathrm{S}_{12}\right)$ along with good antenna matching $\left(\mathrm{S}_{11}, \mathrm{~S}_{22}\right)$ for 2-6GHz operating frequency. HFSS S-Parameters simulation results for different values of Rc are shown in Fig.8. For smaller slot dimensions, both antenna matching and interport isolation is degraded near $3.5 \mathrm{GHz}$ as shown in Fig. 8 for $12 \mathrm{~mm}$ radius of circular slot. On the other hand for larger dimensions of slot in ground plane, the antenna matching and interport isolation degrades around $6 \mathrm{GHz}$ frequency as shown in Fig. 8 for the case of Rc $=16 \mathrm{~mm}$. The is due to reduced ground plane size as already discussed for single port antenna. Although port to port isolation for this case is improved but the upper $10 \mathrm{~dB}$ cut-off frequency is below $6 \mathrm{GHz}$ which is not acceptable for our required design. The circular slot with radius $\mathrm{Rc}=14 \mathrm{~mm}$ has been selected as optimized value for our implemented antenna as it achieves $2-6 \mathrm{GHz}$ $10 \mathrm{~dB}$ antenna input impedance and interport isolation is better than $15 \mathrm{~dB}$ for this case.

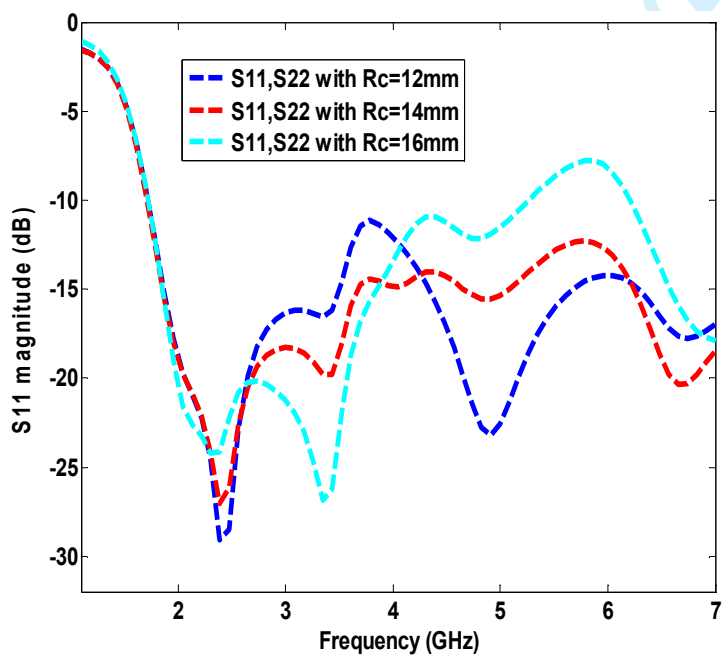

(a)

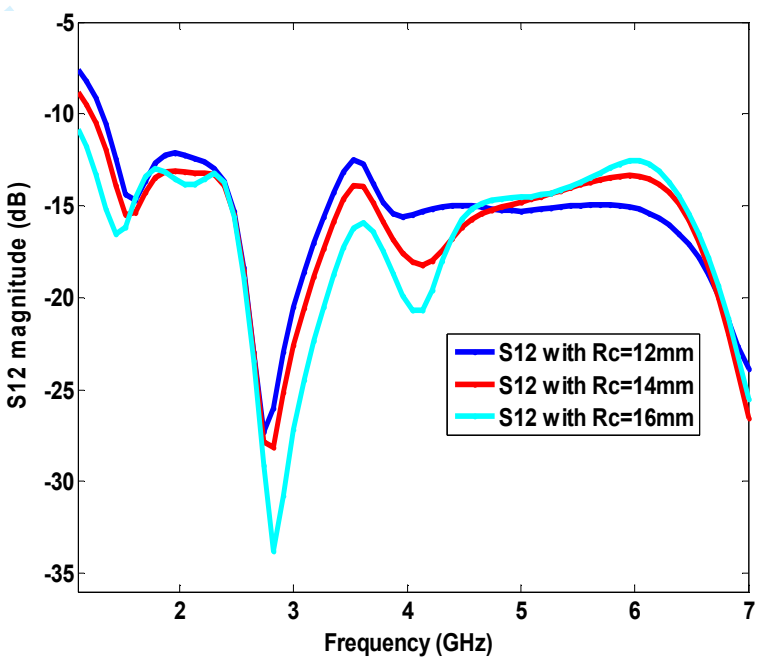

(b)

Fig. 8. HFSS simulation results for (a) $S_{11}, S_{22}$ with different radius $\left(R_{c}\right)$ of circular cut in ground plane (b) $\mathrm{S}_{12}$ with different $\operatorname{radius}\left(\mathrm{R}_{\mathrm{c}}\right)$ of circular cut in ground plane

HFSS simulated peak realized gain for dual port circular disc monopole antenna is shown in Fig. 9 for one port excitation and will be same for other port due to symmetrical 
feeding structure at both ports . The antenna gain varies between $3.2-6.1 \mathrm{dBi}$ in $2-6 \mathrm{GHz}$ operating frequency range.

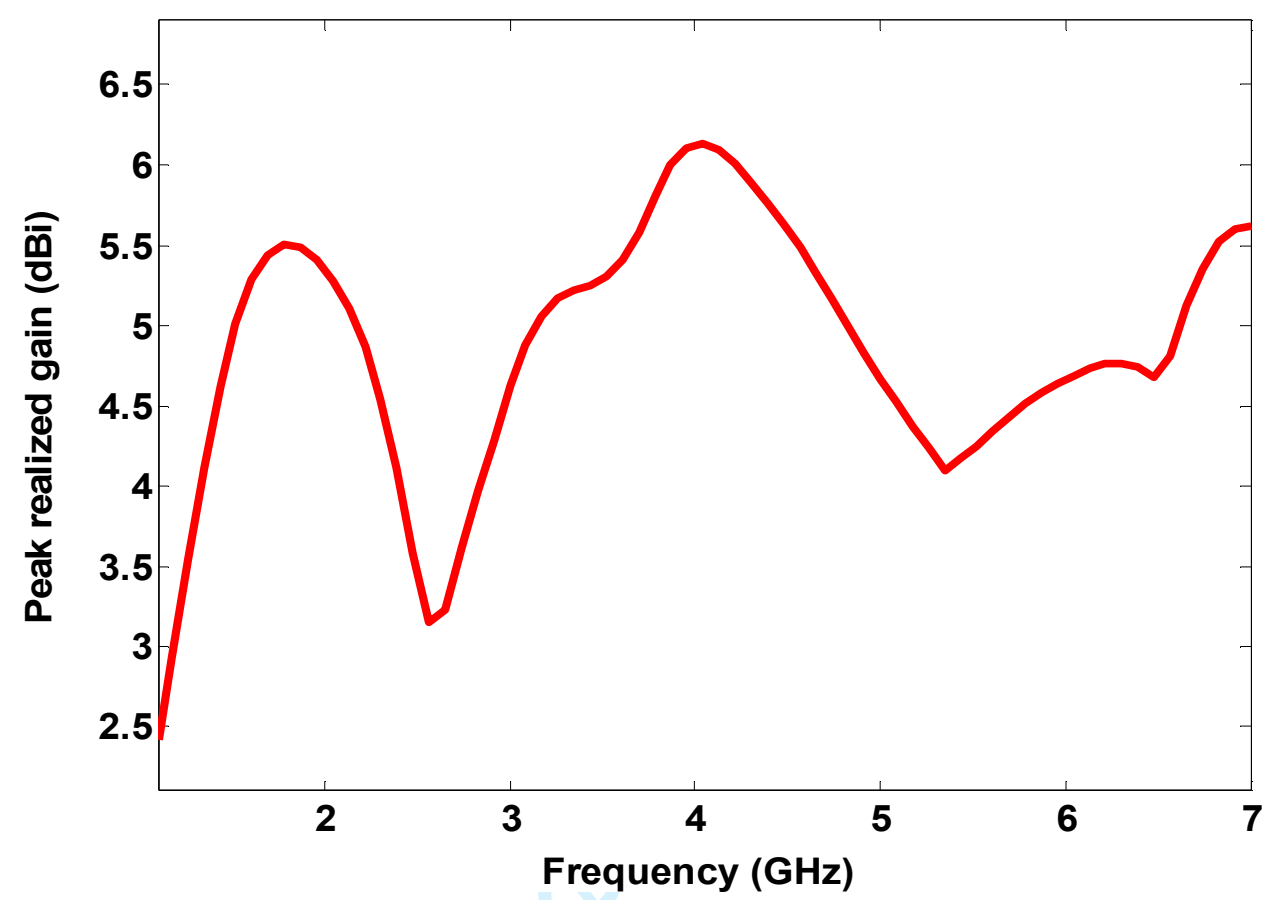

Fig. 9. HFSS simulated peak realized gain for dual port single element circular monopole antenna

\section{Test and measurement results for dual port circular disc monopole antenna}

Implemented dual port circular disc antenna with optimized antenna and ground plane dimensions is printed on $1.575 \mathrm{~mm}$ thick RT5880 substrate (with $\varepsilon=2.2$, tangent loss $=.001$ ) as shown in Fig.6 with Rc=14mm. HFSS simulation and measured $S_{11}, S_{22}$ and $S_{12}$ results for implemented antenna are shown in Fig.10. The measured 10dB lower cut-off frequency of impedance bandwidth for each port starts from $1.7 \mathrm{GHz}$ and upper cut-off frequency extends to more than $7 \mathrm{GHz}$ upper cut-off frequency as clearly indicated in Fig.10 as 10dB impedance band width. Implemented dual port circular disc antenna provides around $15 \mathrm{~dB}$ port to port isolation for $1.7-7 \mathrm{GHz}$ as marked by green dotted line on Fig.10. Thus, the compact implemented dual port antenna based on single circular disc radiator provides a good interport RF isolation over wide range of frequencies. 


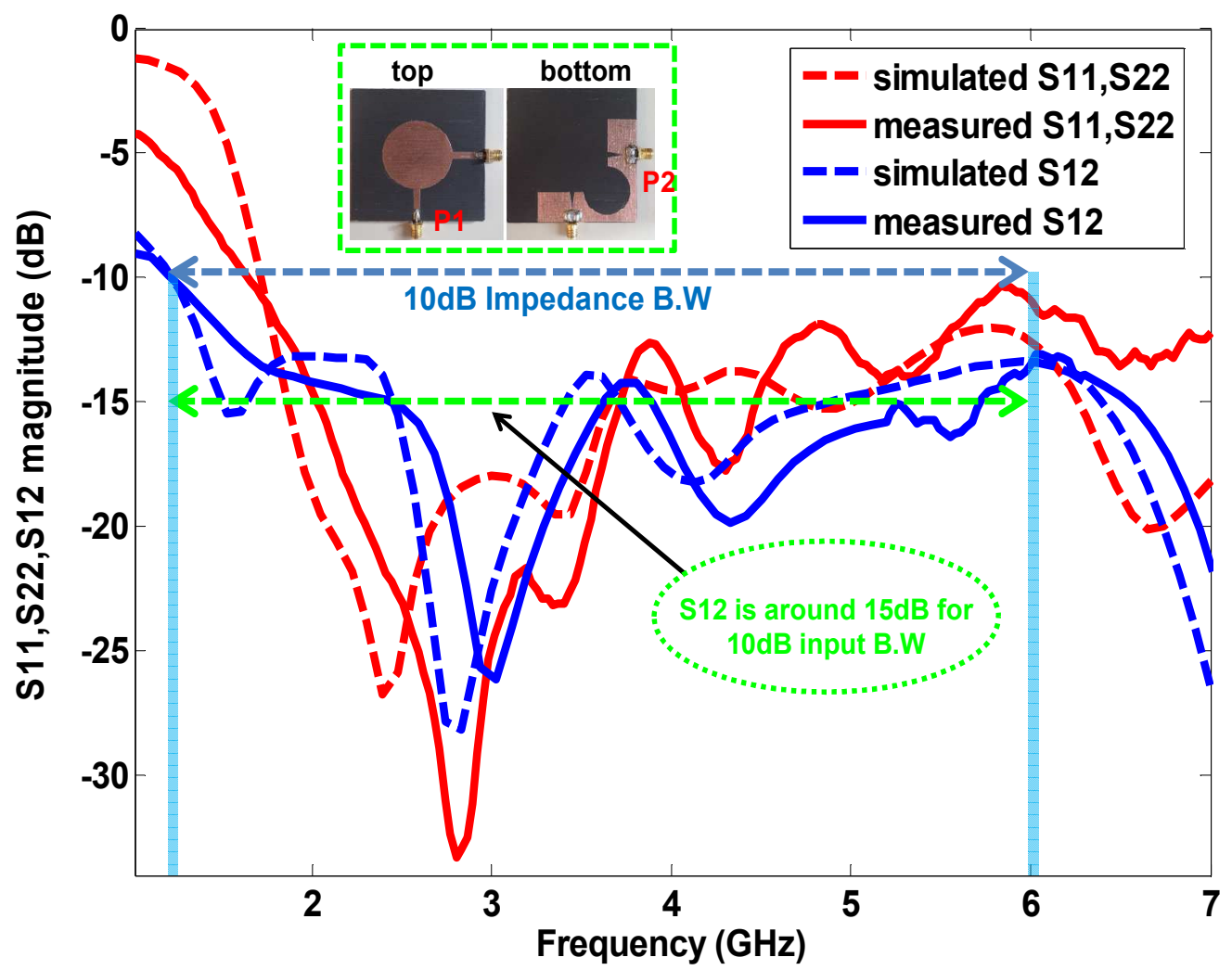

Fig. 10. Simulated vs. measured S-Parameters for dual port circular disc monopole antenna printed on $1.575 \mathrm{~mm}$ thick RT5880 substrate

Simulated and measured E-plane and H-plane gain patterns for implemented antenna at $3 \mathrm{GHz}, 4 \mathrm{GHz}, 5 \mathrm{GHz}$ and $6 \mathrm{GHz}$ frequencies are shown in Fig.11 for port $2\left(\mathrm{P}_{2}\right)$ excitation. Port 1 and Port 2 are along $\mathrm{y}$-axis and $\mathrm{x}$-axis respectively. Therefore for port $1 \mathrm{YZ}$ and $\mathrm{XZ}$ represent E-plane and H-plane respectively while for port $2 \mathrm{XZ}$ is E-Plane and $\mathrm{YZ}$ is $\mathrm{H}$-plane respectively. The antenna deploys same feeding structure to excite the radiating element from other port and measured input matching for second port has also similar characteristics as clear from Fig. 10 so excitation from other port will provide similar but orthogonal radiation patterns. Hence due to symmetry of ports, simulated and measured E-plane and H-plane gain patterns for implemented antenna are sketched only for one port (i.e. port2). 


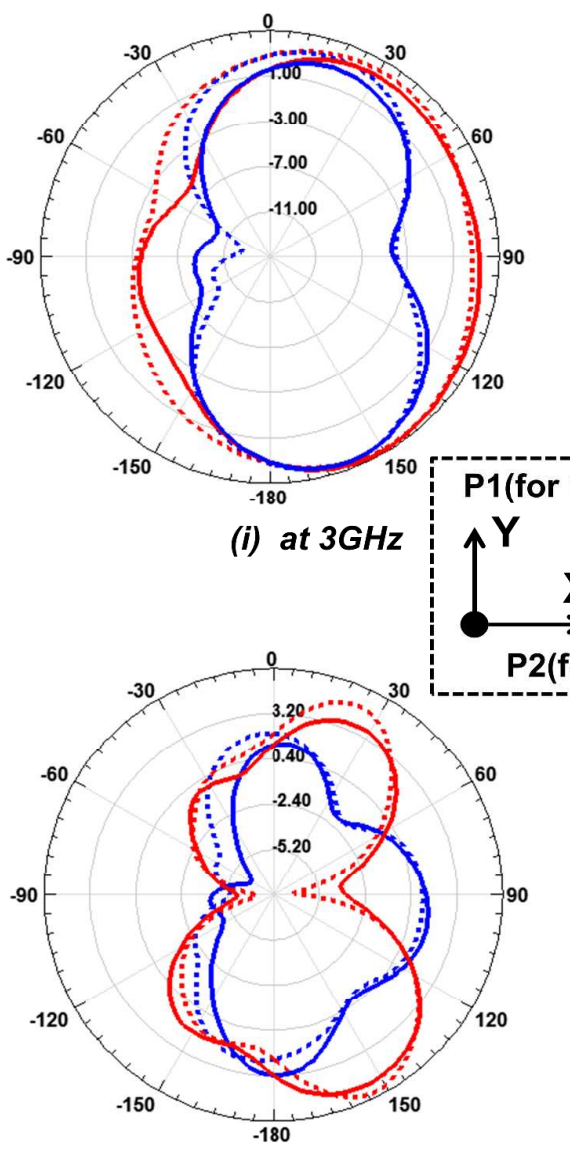

(iii) at $5 \mathrm{GHz}$

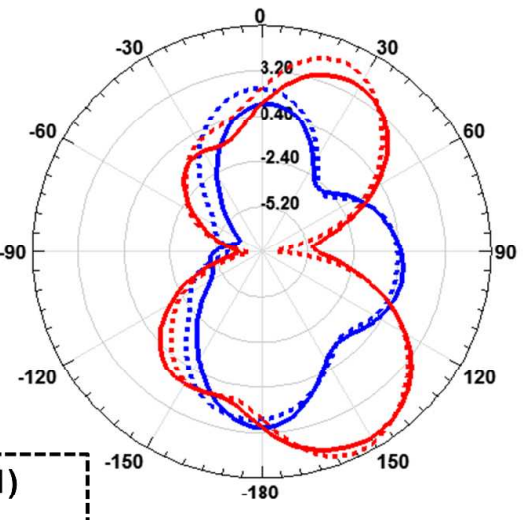

(ii) at $4 \mathrm{GHz}$

Fig. 11. Simulated (dotted lines) vs. measured(solid lines) E-Plane (red lines) and $\mathrm{H}-$ plane(blue lines) gain patterns of dual port antenna at $3 \mathrm{GHz}, 4 \mathrm{GHz}, 5 \mathrm{GHz}$ and $6 \mathrm{GHz}$ for port 1 excitation

Envelope correlation coefficient is another metric or indicator for performance evaluation of multiport antennas used for MIMO applications. The value of envelope correlation coefficient for multiport antennas should be as low as possible to ensure minimum port to port mutual coupling for MIMO antenna operation. Envelope correlation coefficient can be directly determined from far-field patterns but it can be computed using S-parameters results using equation (1) as given in [32]:

$$
\left|\rho_{e}\right|=\frac{\left|s_{11}^{*} s_{12}+s_{21}^{*} s_{22}\right|^{2}}{\left(1-\left(\left|s_{11}\right|^{2}+\left|s_{21}\right|^{2}\right)\right)\left(1-\left(\left|s_{22}\right|^{2}+\left|s_{12}\right|^{2}\right)\right)}
$$


The acceptable antenna's envelope correlation coefficient for reliable MIMO performance is reported to be $<0.5$ [9].

Simulated and measured correlation coefficients computed by simulated and measured S-parameters respectively are shown in Fig. 12.The measured value of envelope correlation coefficient for our antenna is less than 0.02 over required impedance bandwidth which ensures that implemented dual port antenna can be effectively used for MIMO applications over 2-6GHz frequency range.

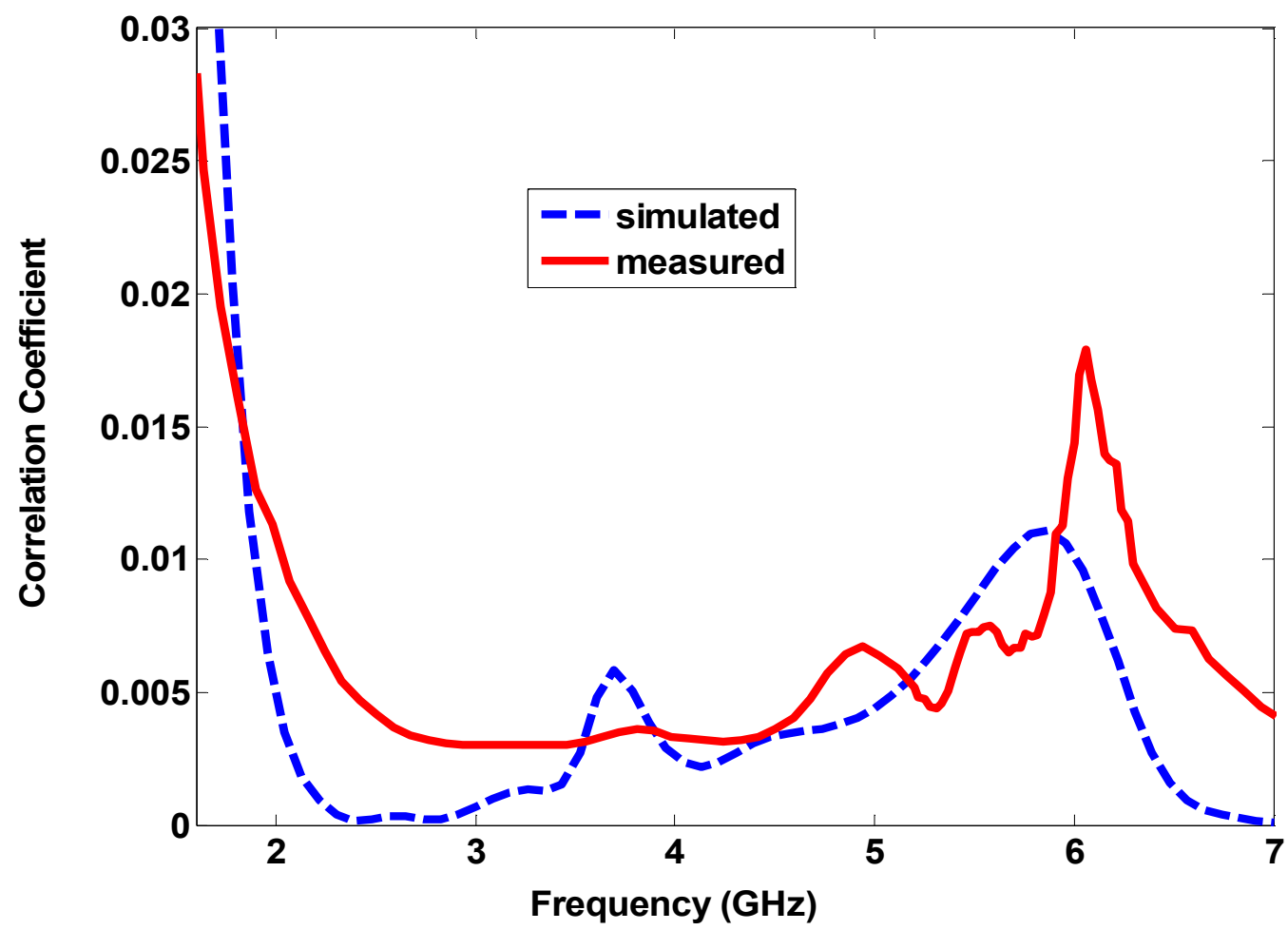

Fig. 12. Simulated and measured correlation coefficient for dual port single element monopole antenna

\section{Conclusion}

A compact $(64 \mathrm{~mm} \times 64 \mathrm{~mm})$ dual port monopole antenna based on single circular disc radiating element has been proposed and implemented for $2-6 \mathrm{GHz}$ MIMO applications. Implemented antenna provides more than $15 \mathrm{~dB}$ port to port RF isolation in target $10-\mathrm{dB}$ impedance bandwidth of $2-6 \mathrm{GHz}$ along with good radiation characteristics. Measured and 
simulated S- parameter, gain patterns and correlation coefficients results are in good agreement for proposed and implemented antenna. The implemented dual port antenna can be effectively used for 2-6GHz MIMO applications based on its nice interport isolation which was also endorsed by correlation coefficients computed by measured S-parameters.

\section{Acknowledgments}

This work was supported in part by The Scientific and Technological Research Council of Turkey (TUBITAK) under Grant 114E494.

\section{References}

[1] L. Malviya, R. K. Panigrahi, and M. V. Kartikeyan, "A $2 \times 2$ dual-band MIMO antenna with polarization diversity for wireless applications," Progress In Electromagnetics Research C, Vol. 61, 91-103, 2016.

[2] G. J. Foschini and J. Gans, "On Limits of Wireless Communications in a Fading Environment when Using Multiple Antennas", Bell Labs Technical Journal, vol. 1, no. 2, Lucent Technologies, pp 41- 59, 1996.

[3] H. Sampath, S. Talwar, J. Tellado, V. Erceg, and A. Paulraj, "A fourth- generation MIMO-OFDM broadband wireless system: Design, performance, and field trial results, "IEEE Commun. Mag., vol. 40, no. 9, pp. 143-149, 2002.

[4] Jayasooriya, C.K.K., Kwon, H.M., Bae, S., et al.: 'Miniaturized circular antennas for MIMO communication systems- pattern diversity'. Int. ITG Workshop on Smart Antennas, 2010, pp. $331-334$

[5] S. B. Sahay, K. C. Bhagwat and P. R. J. Mohan, "Exploitation of MIMO techniques for reliable HF communication," 2012 International Conference on Signal Processing and Communications (SPCOM), Bangalore, 2012, pp. 1-4.

[6] K. Pachori and A. Mishra, "Performance analysis of MIMO systems under multipath fading channels using linear equalization techniques," International Conference on Advances in Computing, Communications and Informatics (ICACCI), 2015, Kochi, 2015, pp. 190-193.

[7] Minz, L., Garg, R.: 'Reduction of mutual coupling between closely spaced PIFAs', Electron. Letters, 2010, 46, (6), pp. 392-394

[8] Park, J., Choi, J., Park, J.-Y., et al.: 'Study of a T-shaped slot with a capacitor for high isolation between MIMO antennas', IEEE Antennas Wirel. Propagation Letters ,2012, 11, pp. 1541-1544

[9] K. Chung, J. H. Yoon,'Integrated MIMO Antenna with High Isolation Characteristic" Electron. Letters, vol. 43, pp. 199-201, 2007. 
[10] T.Y. Wu, S.T. Fang and K.L. Wong, "Printed diversity monopole antenna for WLAN operation," Electron. Letters, 38, (25), pp. 1625-1626, 2002.

[11] C. Jae-Young, et al., "Low correlation MIMO antenna for LTE 700MHz band," in Antennas and Propagation (APSURSI), 2011 IEEE International Symposium on 2011, pp. 2202-2204.

[12] L. Liu, S. W. Cheung and T. I. Yuk, "Compact MIMO Antenna for Portable Devices in UWB Applications," in IEEE Transactions on Antennas and Propagation, vol. 61, no. 8, pp. 4257-4264, Aug. 2013.

[13] Li, H., Xiong, J., Ying, Z., et al.: 'Compact and low profile co-located MIMO antenna structure with polarization diversity and high port isolation', Electron. Letters, 2010, 46, (2), pp. 108-110

[14] S. Soltani and R. D. Murch, "A Compact Planar Printed MIMO Antenna Design," in IEEE Transactions on Antennas and Propagation, vol. 63, no. 3, pp. 1140-1149, March 2015.

[15] A. Toktas and A. Akdagli, "Compact multiple-input multiple-output antenna with low correlation for ultra-wide-band applications," in IET Microwaves, Antennas \& Propagation, vol. 9, no. 8, pp. 822-829, 2015.

[16] C. H. See, R. A. Abd-Alhameed, Z. Z. Abidin, N. J. McEwan and P. S. Excell, "Wideband Printed MIMO/Diversity Monopole Antenna for WiFi/WiMAX Applications," in IEEE Transactions on Antennas and Propagation, vol. 60, no. 4, pp. 2028-2035, April 2012.

[17] X. S. Yang, L. Zhang, L. L. Zhou, R. Q. Wang and X. J. Li, "Planar two-element UWB MIMO antennas with high isolations," IEEE International Conference on Computational Electromagnetics (ICCEM), Hong Kong, 2015, pp. 363-365

[18] C. M. Luo, J. S. Hong and L. L. Zhong, "Isolation Enhancement of a Very Compact UWBMIMO Slot Antenna With Two Defected Ground Structures," in IEEE Antennas and Wireless Propagation Letters, vol. 14, no. , pp. 1766-1769, 2015

[19] M. S. Khan, A. D. Capobianco, A. Naqvi, B. Ijaz, S. Asif and B. D. Braaten, "Planar, compact ultra-wideband polarization diversity antenna array," in IET Microwaves, Antennas \& Propagation, vol. 9, no. 15, pp. 1761-1768, 12102015

[20] Chen, S.C., and Wang, Y.S.: 'A decoupling technique for increasing the port isolation between two strongly coupled antennas', IEEE Transactions on Antennas Propagation , 2008, 56, pp. $3650-3658$

[21] Xian, Q., Hui, L.W., and Sailing, H.: 'A decoupling technique for increasing the port isolation between two closely packed antennas'. Antennas and Propagation Society Int. Symp., Chicago, IL, USA, July2012, pp. 1-2

[22] Skycross, Inc, iMAT Antenna Whitepaper, January 2008, http://www.skycross.com/.

[23] N.K. Kiem, D.N. Dinh, H.T. Viet, \& D.N. Chien, "A novel design of dual-feed single-element antenna for 4G MIMO terminals", Progress in Electromagnetics Research Symposium, pp. 1827, 2012. 
[24] F. M. Caimi, and M. Mongomery, "Dual feed, single element antenna for WiMAX MIMO application," International Journal of Antennas and Propagation, Vol. 2008, Article ID 219838, 5 pages, 2008.

[25] T. Aboufoul, A. Alomainy and C. Parini, "A planar dual fed UWB monopole antenna with polarization diversity for cognitive radio sensing," Antennas and Propagation Conference (LAPC), 2012 Loughborough, Loughborough, 2012, pp. 1-4.

[26] Moradikordalivand, Alishir, et al. "Dual polarized MIMO antenna system for WiFi and LTE wireless access point applications." International Journal of Communication Systems (2014)

[27] Nawaz, H. and Tekin, I., "Dual port single patch antenna with high interport isolation for $2.4 \mathrm{GHz}$ in-band full duplex wireless applications". Microw. Opt. Technol. Lett., 58: 1756-1759. doi: 10.1002/mop.29899, 2016

[28] K. P. Ray, "Design Aspects of Printed Monopole Antennas for Ultra-Wide Band Applications," International Journal of Antennas and Propagation, vol. 2008, Article ID 713858, 8 pages, 2008. doi:10.1155/2008/713858

[29] N. P. Agrawall, G. Kumar and K. P. Ray, "Wide-band planar monopole antennas," in IEEE Transactions on Antennas and Propagation, vol. 46, no. 2, pp. 294-295, Feb 1998.

[30] Jianxin Liang, C. C. Chiau, Xiaodong Chen and C. G. Parini, "Study of a printed circular disc monopole antenna for UWB systems," in IEEE Transactions on Antennas and Propagation, vol. 53, no. 11, pp. 3500-3504, Nov. 2005.

[31] Gilliard N. Malheiros-Silveira, Ricardo T. Yoshioka, Jose E. Bertuzzo, and Hugo E. HernandezFigueroa, "Printed monopole antenna with triangular-shape groove at ground plane for blue-tooth and UWB applications," Microwave and Optical Technology Letters, vol. 57, no. 1, pp. 28-31, 2014.

[32] S. Blanch, J. Romeu, and I. Corbella, "Exact representation of antenna system diversity performance from input parameter description," Electronics Letters, vol. 39, no. 9, pp. 705-707, 2003. 